\title{
Alto riesgo obstétrico FERNANDO SANCHEZ TORRES
}

Primera edición. Editorial Universidad Nacional de Colombia, Colección Biblioteca Básica Bogotá, 1988. Un volumen de 314 páginas. Tapa rústica, plastificada, en varios colores con reproducción de un cuadro del autor. Mide 23.9 por $16,5 \mathrm{cms}$. Mancha de 18,7 por $12,6 \mathrm{cms}$. Papel bond 20. Letra de 10 puntos. Tiene 44 figuras, 5 tablas, 11 fotografías: 5 en blanco y negro y 6 a color.

Es un manual dividido en seis capítulos: vigilancia antenatal, Patología médica antenatal, Vigilancia intraparto, Patología intraparto y Apéndice. En el primero de ellos destacan los factores que intervienen en la calidad de la atención gíneco-obstéirica perinatológica, hace un análisis bien documentado de las drogas y sustancias a evitar y tiene un resumen actualizado sobre la drogadicción y el tratamiento de las principales alteraciones congénitas. Contiene, también, la terminología obstétrica aceptada internacionalmente.

En la patología médica asociada al embarazo sobresalen los temas sobre diabetes y toxoplasmosis, por la claridad con que se exponen, y el de insuficiencia renal aguda, por la profundidad con que se actualiza.

Creemos que el capítulo sobre patología obstétrica antenatal es, quizás, el mejor logrado, al enfocar las principales patologías en forma muy clara, esquemática y, a la vez, actualizada.

Nos llamó la atención la forma de exponer los temas de parto prematuro y toxemia gravídica. Destaca igualmente, en el capítulo de patología intraparto, los tópicos

* Jefe de la Catedra de Clínica Obstétrica B., Escuela de Medicina Luis "Razetti, Universidad Central de Venezuela. Rev Obstet Ginecol Venezuela 1990; 50: 101. sobre antecedentes de cesárea, ruptura e inversión uterina aguda.

En resumen, creemos que estamos en presencia de un Manual de Alto Riesgo Obstétrico muy bien logrado, escrito por un gran especialista latinoamericano, con dilatada trayectoria en docencia universitaria en su país, Colombia, quien; como él mismo expresa en la presentación de su obra, ha querido dedicarla básicamente a los médicos generales, estudiantes de Medicina y a los profesionales que se inician en la especialidad.

En el apéndice destacan la buena documentación sobre las sustancias ocitócicas, el manejo del tromboembolismo grávido-puerperal y el sìempre controversial aspecto de las indicaciones médicas para la anticoncepción femenina permanente.

Aplaudimos el logro del objetivo que se propuso el autor, en base a su sencillez didáctica, sin por eso abandonar la profundidad y la actualización científica de los diferentes tópicos tratados.

El otro mérito que la adjudicamos a la obra del doctor Sánchez Torres es su constante preocupación por el enfoque Nacional y Regional de la patología más frecuente, y su manejo con base en nuestros recursos y experiencias, hecho éste, por lo demás, fácil de comprobar por la abundante y bien seleccionada bibliografía latinoamericana referida en los diversos índices, entre los cuales, por cierto, se citan numerosas producciones venezolanas.

\section{"Contra Viento y Marea 25 Años de Planificación Familiar en Colombia” GONZALO ECHEVERRY PARRA}

La Asociación Colombiana para el Estudio de la Población, ACEP, y la Asociación Pro-Bienestar de la Familia Colombiana, PROFAMILIA, celebraron recientemente sus 25 años de labores en los terrenos de la demografía, la investigación, las publicaciones, la educación sexual y la planificación familiar, y con tal motivo prepararon la edición de la obra titulada "CONTRA VIENTO Y MAREA - 25 Años de Planificación Familiar en Colombia", escrita por Gonzalo Echeverry Parra, conocido médico ginecólogo quien durante casi tres quinquenios fue Director de PROFAMILIA. Ha prolongado esta publicación el distinguido hombre de letras y diplomático Dr. Pedro Gómez Valderrama, miembro fundador y expresidente de ACEP. La obra presenta un muy documentado relato histórico de todas las luchas, las experiencias y los logros vividos por toda la pléyade de pioneros y continuadores de esta inmensa labor, cuyo resultado ha sido un descenso tan notorio de las tasas de incremento poblacional que ha merecido el calificativo de "El Milagro Colombiano". El autor investigó los antecedentes y las organizaciones que promovieron los programas, y contactó a las personas que hicieron posible su exitoso desarrollo. La obra incluye los antecedentes de la problemática de la población hasta 1960; un recuento de los programas en las décadas de los 60 y 70; desarrollo de los programas entre 1970 y 1990; y, por último, el estado actual y las perspectivas de población, salud reproductiva y planificación familiar. Es particularmente grata la lectura de esta obra gracias al donoso estilo y la pureza idiomática de que hace gala el autor, caracterizados por un proceso anecdótico y ameno que lleva con grado al lector a través de la secuencia de hechos históricos, datos estadísticos y comentarios personales que Gonzalo Echeverry ha amalgamado con armonía. 